\title{
Empirical Probability of Positive Response to PEEP Changes and Mechanical Ventilation Factors Associated With Improved Oxygenation During Pediatric Ventilation
}

\author{
Craig D Smallwood, Brian K Walsh, John H Arnold, and Andrew Gouldstone
}

\begin{abstract}
BACKGROUND: PEEP is titrated to improve oxygenation during mechanical ventilation. It is clinically desirable to identify factors that are associated with a clinical improvement or deterioration following a PEEP change. However, these factors have not been adequately described in the literature. Therefore, we aimed to quantify the empirical probability of PEEP changes having a positive effect upon oxygenation, compliance of the respiratory system $\left(C_{R S}\right)$, and the ratio of dead space to tidal volume $\left(\mathrm{V}_{\mathrm{D}} / \mathrm{V}_{\mathrm{T}}\right)$. Further, clinical factors associated with positive response during pediatric mechanical ventilation are described. METHODS: Mechanically ventilated pediatric subjects in the ICU were eligible for inclusion in the study. During PEEP increases $\left(\right.$ PEEP $\left._{\text {increase }}\right)$, a responder was defined as having an improved $\mathrm{S}_{\mathrm{pO}_{2}} / \mathrm{F}_{\mathrm{IO}_{2}}$ ratio; non-responders demonstrated a worsening $\mathrm{S}_{\mathrm{pO}_{2}} / \mathrm{F}_{\mathrm{IO}_{2}}$ ratio in the following hour. When PEEP was decreased (PEEP ${ }_{\text {decrease }}$ ), a responder was anyone who maintained or increased the $\mathrm{S}_{\mathrm{pO}_{2}} / \mathrm{F}_{\mathrm{IO}_{2}}$ ratio; non-responders demonstrated a worsening $\mathrm{S}_{\mathrm{pO}_{2}} / \mathrm{F}_{\mathrm{IO}_{2}}$ ratio. Features from continuous mechanical ventilation variables were extracted, and differences between responders and non-responders were identified. RESULTS: 286 PEEP change cases were eligible for analysis in 76 subjects. For PEEP increase $_{\text {cases, the empir- }}$ ical probability of positive response was $56 \%, 67 \%$, and $54 \%$ for oxygenation, $C_{R S}$, and $V_{D} / V_{T}$, respectively. The median $\mathrm{S}_{\mathrm{pO}_{2}} / \mathrm{F}_{1 \mathrm{IO}_{2}}$ increase was 13. For PEEP ${ }_{\text {decrease }}$, the empirical probability of response was $46 \%, 53 \%$, and $46 \%$ for oxygenation, $C_{R S}$, and $V_{D} / V_{T}$, respectively. PEEP $P_{\text {increase }}$ responders had higher $\mathrm{F}_{\mathrm{IO}}$ requirements $(70.8$ vs $52.5 \%, P<.001)$, mean airway pressure $(14.0 \mathrm{vs}$ $\left.12.9 \mathrm{~cm} \mathrm{H} \mathrm{H}_{2} \mathrm{O}, P=.03\right)$, and oxygen saturation index $(9.9 \mathrm{vs} 7.5, P=.002)$ versus non-responders. For PEEP ${ }_{\text {decrease}}, V_{\mathrm{D}} / \mathrm{V}_{\mathrm{T}}$ was lower in responders $(0.46$ vs $0.50, P=.031)$. CONCLUSIONS: In children requiring mechanical ventilation, the responder rate was modest for both PEEP $_{\text {increase }}$ and PEEP $_{\text {decrease }}$ cases. These data suggest that PEEP titration often does not have the desired clinical effect, and predicting which patients will manifest a positive response is complex, requiring more sophisticated means of assessing individual subjects. Key words: mechanical ventilation; positive end-respiratory pressure; oxygenation; dead-space ventilation; pediatrics. [Respir Care 2019;64(10):1193-1198. @ 2019 Daedalus Enterprises]
\end{abstract}

\section{Introduction}

In mechanically ventilated children with hypoxic respiratory failure, PEEP titration is typically implemented to

Dr Smallwood and Dr Arnold are affiliated with Division of Critical Care Medicine, Department of Anesthesia, Critical Care and Pain Medicine, Boston Children's Hospital, Boston, Massachusetts and Harvard Medical School, Boston, Massachusetts. Dr Smallwood and Dr Gouldstone are affiliated with Department of Bioengineering, Northeastern University, Boston, Massachusetts. Dr Walsh is affliated with Department of Respiratory Therapy, Liberty University, Lynchburg, Virginia. Dr Gouldstone improve oxygenation through the reversal of atelectasis and prevention of further alveolar collapse. However, PEEP can ameliorate or exacerbate lung injury. ${ }^{1}$ PEEP changes are frequently made at the bedside, but little guidance exists in the pediatric literature to predict who is likely to respond to an intervention. The physiologic rationale for increasing PEEP in most cases is to improve functional

\footnotetext{
is affliated with Department of Mechanical and Industrial Engineering, Northeastern University, Boston, Massachusetts.
}

The authors have disclosed no conflicts of interest 
residual capacity and to reduce the physiologic ratio of dead space to tidal volume $\left(\mathrm{V}_{\mathrm{D}} / \mathrm{V}_{\mathrm{T}}\right)$, shunt fraction, and ventilation/perfusion mismatch. ${ }^{2-4}$ Although the use of moderate to high levels of PEEP has been shown to be safe

\section{See the Related Editorial on Page 1319}

in the pediatric population, ${ }^{5-8}$ widespread and consistent application has not been recommended.9,10 Oxygenation is an important clinical target in pediatric subjects because it is associated with lower mortality during severe illness, such as ARDS. ${ }^{11,12}$ Despite the importance of oxygenation, there is a paucity of investigations reporting the proportion of PEEP changes that are associated with a positive response, and investigations targeting PEEP management are needed. ${ }^{13}$ Therefore, we sought to quantify the proportion of PEEP changes that had a positive effect on oxygenation in children receiving mechanical ventilation and to identify factors that could be readily obtained at the bedside that are associated with response.

\section{Methods}

Subjects were enrolled in the study if they were admitted to the pediatric ICU, age was $<18 \mathrm{y}$, they received mechanical ventilation for $>24 \mathrm{~h}$, continuous mechanical ventilation data were recorded during that time period, and they exhibitted hypoxic respiratory failure defined as an oxygen saturation index $\geq 5 .{ }^{9}$

All subjects were mechanically ventilated (Servo-i, Getinge AB-Maquet, Gothenburg, Sweden) and connected to a bedside physiologic monitor (IntelliVue MP90, Philips Healthcare, Andover, Massachusetts). A medical device-interfacing module (IntelliBridge EC10, Philips Healthcare) was used to connect the mechanical ventilator and monitor to a research server. Data were recorded at a frequency of $0.2 \mathrm{~Hz}$ for the duration of invasive mechanical ventilation in the ICU. Demographic and outcome data were abstracted from the medical record for each subject, and the diagnosis was recorded according to the ICD-9 and ICD-10 codes and binned to either primary respiratory, surgical procedure, neurologic, sepsis, or other. ${ }^{14}$ The modified Bohr $\mathrm{V}_{\mathrm{D}} / \mathrm{V}_{\mathrm{T}}$ was calculated according to established methods. ${ }^{15,16}$ Usual ventilator management included lung-protective strategies where appropriate (permissive hypercapnia, tidal volumes $\sim 5-8 \mathrm{~mL} / \mathrm{kg}$ ),

Correspondence: Craig D Smallwood PhD RRT, Division of Critical Care Medicine, Department of Anesthesia, Critical Care and Pain Medicine, Boston Children's Hospital, 300 Longwood Ave., Bader Building 634, Boston, MA 02115. E-mail: craig.smallwood@childrens.harvard.edu.

DOI: $10.4187 /$ respcare.06707

\section{QUICK LOOK}

\section{Current knowledge}

PEEP is typically titrated to improve oxygenation during mechanical ventilation, but can be adjusted to impact compliance and hemodynamics. PEEP can ameliorate or exacerbate lung injury.

\section{What this paper contributes to our knowledge}

In children requiring mechanical ventilation, improvements in oxygenation were observed only in 56\% and $46 \%$ of PEEP increases and decreases, respectively. These data suggest that PEEP titration often does not have the desired clinical effect, particularly during ventilator weaning.

titration of PEEP according to the $\mathrm{S}_{\mathrm{pO}_{2}}$ and $\mathrm{F}_{\mathrm{IO}_{2}}$ requirement, and maintenance of endotracheal tube leak to be $<10 \%$.

Both the physiologic monitor and mechanical ventilator offer built-in preprocessing inclusive of artifact detection. However, these signals can still be corrupted by noise and artifact. ${ }^{17}$ A band-pass filter was applied to physiologic data to filter out data that were beyond the physiologic range according to established methods. ${ }^{18}$

For all included subjects, an instance where PEEP was manipulated was identified to assess response to PEEP and extract data from the required time period. These PEEP cases were defined as a 2-h period: $1 \mathrm{~h}$ preceding and $1 \mathrm{~h}$ following a change in PEEP. This time frame has been reported as the time required to achieve equilibration of pulmonary compliance and oxygenation following modest changes in PEEP level in mechanically ventilated children. ${ }^{19}$ A quality function was built to ensure that only clean cases were analyzed. A clean PEEP case was defined as one in which no ventilator changes were made (other than PEEP and $\mathrm{F}_{\mathrm{IO}_{2}}$ ); the PEEP change was sustained for $>1 \mathrm{~h}$.

For cases in which the PEEP was increased, a responder was defined as an individual who exhibited any improvement in oxygenation by $\mathrm{S}_{\mathrm{pO}_{2}} / \mathrm{F}_{\mathrm{IO}_{2}}$ ratio, dynamic compliance of the respiratory system $\left(\mathrm{C}_{\mathrm{RS}}\right)$, or $\mathrm{V}_{\mathrm{D}} / \mathrm{V}_{\mathrm{T}} ;\left[x_{\text {post }}-x_{\text {pre }}\right]>0$ (where $x=\left[\mathrm{S}_{\mathrm{pO}_{2}} / \mathrm{F}_{\mathrm{IO}_{2}}\right.$ ratio, $\left.\left.\mathrm{C}_{\mathrm{RS}}, \mathrm{V}_{\mathrm{D}} / \mathrm{V}_{\mathrm{T}}\right]\right)$. For cases in which PEEP was decreased, a responder was defined as an individual in whom $\mathrm{S}_{\mathrm{pO}_{2}} / \mathrm{F}_{\mathrm{IO}_{2}}$ ratio, $\mathrm{C}_{\mathrm{RS}}$, or $\mathrm{V}_{\mathrm{D}} / \mathrm{V}_{\mathrm{T}}$ was maintained; $\left[x_{\text {post }}-x_{\text {pre }}\right]$ (where $\left.x=\left[\mathrm{S}_{\mathrm{pO}_{2}} / \mathrm{F}_{\mathrm{IO}_{2}}, \mathrm{C}_{\mathrm{RS}}, \mathrm{V}_{\mathrm{D}} / \mathrm{V}_{\mathrm{T}}\right]\right) \geq 0$.

The D'Agostino and Pearson omnibus test was applied to test the normality of the data. Because the data were not normally distributed, continuous variables are presented as median values with interquartile ranges (IQR). Subjects had multiple cases where PEEP was increased or decreased. To account for this, generalized estimating equations were utilized to compare continuous demographic and respiratory features and categorical features between responders 
Table 1. Description of the Study Population

\begin{tabular}{lc}
\hline \multicolumn{1}{c}{ Parameter } & Value \\
\hline Age, y & $1.9(0.9-6.6)$ \\
Sex, $n$ female $(\%)$ & $38(50)$ \\
Weight, kg & $10.3(7.1-20.0)$ \\
Height, cm & $80(65-109)$ \\
Ventilation duration, d & $5.7(3.4-14.4)$ \\
ICU length of stay, d & $11.0(5.7-20.9)$ \\
Hospital length of stay, d & $22.0(7.5-108.1)$ \\
Primary diagnosis, $n(\%)$ & \\
Respiratory & $25(33)$ \\
Surgical & $18(24)$ \\
Sepsis & $6(8)$ \\
Neurologic & $5(7)$ \\
Other & $22(29)$
\end{tabular}

Continuous values are expressed as median (interquartile range) unless otherwise indicated.

and non-responders (by $\mathrm{S}_{\mathrm{pO}_{2}} / \mathrm{F}_{\mathrm{IO}_{2}}$ ratio). Data aggregation, cleaning, and analyses were conducted using MATLAB (V9.1.0.441655, Mathworks, Natick, Massachusetts). Statistical analyses were performed using SPSS v. 23 (SPSS, Chicago, Illinois). The study protocol was approved by the institutional review board.

\section{Results}

In total, 76 subjects demonstrated PEEP change cases that were included in the analysis. A description of the population is shown in Table 1. A total of 286 PEEP cases were analyzed (ie, 166 increases and 120 decreases). The PEEP was increased by 1,2 and $\geq 3 \mathrm{~cm} \mathrm{H}_{2} \mathrm{O}$ in $58 \%$, $26 \%$, and $16 \%$ of the cases, respectively. The PEEP was decreased by 1,2 and $3 \mathrm{~cm} \mathrm{H}_{2} \mathrm{O}$ in $80 \%, 17 \%$, and $3 \%$ of the cases, respectively. In the $\mathrm{PEEP}_{\text {increase }}$ cases, the empirical probability of positive response was $56 \%, 67 \%$, and $54 \%$ for $\mathrm{S}_{\mathrm{pO}_{2}} / \mathrm{F}_{\mathrm{IO}_{2}}$ ratio, $\mathrm{C}_{\mathrm{RS}}$, and $\mathrm{V}_{\mathrm{D}} / \mathrm{V}_{\mathrm{T}}$, respectively. For $\mathrm{PEEP}_{\text {decrease, }}$, the empirical probability of acceptable response was $46 \%, 53 \%$, and $46 \%$ for oxygenation, mechanics, and $\mathrm{V}_{\mathrm{D}} / \mathrm{V}_{\mathrm{T}}$, respectively.

There were statistically significant differences in ventilation parameters in the hour preceding the PEEP change in the $\mathrm{PEEP}$ increase group; responders had higher $\mathrm{F}_{\mathrm{IO}_{2}}(70.8 \%$ vs $52.5 \%, P<.001)$, higher mean airway pressure $(14.0$ vs $12.9 \mathrm{~cm} \mathrm{H}_{2} \mathrm{O}, P=.03$ ), and increased oxygen saturation index (9.9 vs 7.5, $P=.002$ ) in the hour preceding the PEEP change compared to non-responders (Table 2).

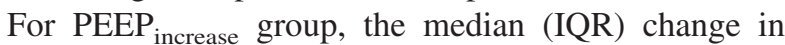
$\mathrm{S}_{\mathrm{pO}_{2}} / \mathrm{F}_{\mathrm{IO}_{2}}$ ratio was $13(5-30)$ and $-19(-40$ to -7$)$ for responders and non-responders, respectively. For decreases in PEEP, the responder rate was $47 \%$, and $\mathrm{V}_{\mathrm{D}} / \mathrm{V}_{\mathrm{T}}$ was lower in responders compared to non-responders ( 0.46 vs $0.50, P=.031$ ) (Table 3 ). For the $\mathrm{PEEP}_{\text {decrease }}$ group, the median (IQR) change in $\mathrm{S}_{\mathrm{pO}_{2}} / \mathrm{F}_{\mathrm{IO}_{2}}$ ratio was 8 (3-21) and $-8(-16$ to -3$)$ for responders and non-responders, respectively. There were no differences in age, weight, height, or sex between responders and non-responders for either the $\mathrm{PEEP}_{\text {increase }}$ group or the $\mathrm{PEEP}_{\text {decrease }}$ group.

\section{Discussion}

Quantifying the proportion of PEEP changes having a positive or acceptable effect on oxygenation in children is important. Our data show that, when increasing PEEP as a part of routine care, oxygenation was improved in just over half $(56 \%)$ of the cases. Responders demonstrated worse lung injury relative to non-responders with significantly greater $\mathrm{F}_{\mathrm{IO}_{2}}$ requirements, mean airway pressure, and oxygen saturation index in the hour preceding the change. On the other hand, just under half (47\%) of cases demonstrated acceptable oxygenation following a decrease in PEEP. There were no differences in the demographic or ventilator features between $\mathrm{PEEP}_{\text {decrease }}$ responders and non-responders.

Most pediatric experimental and clinical investigations including PEEP titration have been done in combination with a recruitment maneuver.6,20-22 Few studies in the pediatric literature have assessed the titration of PEEP without a recruitment maneuver. In the adult literature, end-expiratory transpulmonary pressure, ${ }^{23}$ dynamic compliance, ${ }^{24}$ dead space, ${ }^{25}$ electrical impedance tomography, computed tomography, ${ }^{26}$ and ultrasonography ${ }^{27}$ have been proposed as methods to individualize or assess PEEP titration. In a cohort of adult subjects with ARDS, Pintado et $\mathrm{al}^{28}$ assessed the utility of an individualized approach to setting PEEP based on best pulmonary compliance. The authors did not report the success of individual PEEP changes but did note that, in the compliance-guided group, the $\mathrm{P}_{\mathrm{aO}} / \mathrm{F}_{\mathrm{IO}_{2}}$ ratio was 146 compared to 133 in the control group. However, this finding was not statistically significant and represented only a trend. In our study, we sought to quantify the number of PEEP changes that would be classified as responders or non-responders. Further, mechanically ventilated children have been noted to have distinct pathophysiologic characteristics during lung injury compared to adults; children have increased chest wall compliance, preserve the function of surfactant during lung injury, and have immune response that are different from those of adult subjects. ${ }^{29-31}$ Head-to-head comparison with adult studies must be done with this in mind.

Weaning from mechanical ventilation includes stepped reduction in ventilator support (including PEEP) and comprises up to $40 \%$ of the total duration of ventilation. ${ }^{32}$ In children, efforts to introduce protocols for ventilator weaning have demonstrated mixed results. ${ }^{33-35}$ Inappropriate application of PEEP can result in alveolar over distention, increased work of breathing, worsening ventilation-perfusion matching, as well as effects on the circulatory system 


\section{Factors Associated With PEEP Responsiveness}

Table 2. Comparison Between PEEP Responders and Non-Responders Following a PEEP Increase

\begin{tabular}{|c|c|c|c|}
\hline Clinical Parameter & Responders* & Non-Responders & $P$ \\
\hline $\mathrm{C}_{\text {dyn }}, \mathrm{mL} / \mathrm{kg} / \mathrm{cm} \mathrm{H}_{2} \mathrm{O}$ & $0.42(0.25-0.53)$ & $0.44(0.29-0.50)$ & .60 \\
\hline PEEP, $\mathrm{cm} \mathrm{H}_{2} \mathrm{O}$ & $8(6-10)$ & $7(5-8)$ & .44 \\
\hline $\mathrm{S}_{\mathrm{pO}_{2}}, \%$ & $95(93-97)$ & $94(93-96)$ & .45 \\
\hline $\mathrm{P}_{\text {peak }}, \mathrm{cm} \mathrm{H}_{2} \mathrm{O}$ & $24(22-28)$ & $23(20-26)$ & .21 \\
\hline $\mathrm{F}_{\mathrm{IO}_{2}}, \%$ & $71(55-86)$ & $52(46-65)$ & $<.001$ \\
\hline $\mathrm{V}_{\mathrm{T}}, \mathrm{mL} / \mathrm{kg}$ & $6.0(5.0-7.2)$ & $6.7(5.3-7.2)$ & .43 \\
\hline Breathing frequency, breaths/min & $28(24-36)$ & $27(24-32)$ & .37 \\
\hline$\overline{\mathrm{P}}_{\mathrm{aw}}, \mathrm{cm} \mathrm{H}_{2} \mathrm{O}$ & $14.0(11.9-16.5)$ & $13.0(10.8-14.8)$ & .03 \\
\hline Oxygen saturation index & $9.9(7.4-14.8)$ & $7.5(5.7-8.4)$ & .002 \\
\hline $\mathrm{V}_{\mathrm{D}} / \mathrm{V}_{\mathrm{T}}$ & $0.47(0.42-0.52)$ & $0.44(0.40-0.51)$ & .52 \\
\hline$\Delta \mathrm{PEEP}, n(\%)$ & $1(1-2)$ & $1(1-2)$ & .73 \\
\hline $1 \mathrm{~cm} \mathrm{H}_{2} \mathrm{O}$ & $59(63)$ & $37(51)$ & \\
\hline $2 \mathrm{~cm} \mathrm{H}_{2} \mathrm{O}$ & $19(20)$ & $24(26)$ & \\
\hline $3 \mathrm{~cm} \mathrm{H}_{2} \mathrm{O}$ & $14(15)$ & $11(15)$ & \\
\hline $4 \mathrm{~cm} \mathrm{H}_{2} \mathrm{O}$ & $2(2)$ & $0(0)$ & \\
\hline \multicolumn{4}{|c|}{$\begin{array}{l}\text { Continuous values are expressed as median (interquartile range) unless otherwise indicated. } \\
\text { * Responders were defined as those demonstrating oxygenation improvement in the first hour following the PEEP change relative to the preceding hour. } \\
\mathrm{C}_{\mathrm{dyn}}=\text { dynamic respiratory system compliance } \\
\mathrm{P}_{\text {peak }}=\text { peak airway pressure } \\
\mathrm{V}_{\mathrm{T}}=\text { tidal volume } \\
\overline{\mathrm{P}}_{\text {aw }}=\text { mean airway pressure } \\
\mathrm{V}_{\mathrm{D}}=\text { dead space volume }\end{array}$} \\
\hline
\end{tabular}

Table 3. Comparison Between PEEP Responders and Non-Responders Following a PEEP Decrease

\begin{tabular}{|c|c|c|c|}
\hline Clinical Parameter & Responders* & Non-Responders & $P$ \\
\hline $\mathrm{C}_{\mathrm{dyn}}, \mathrm{mL} / \mathrm{kg} / \mathrm{cm} \mathrm{H}_{2} \mathrm{O}$ & $0.45(0.38-0.60)$ & $0.48(0.32-0.54)$ & .41 \\
\hline PEEP, $\mathrm{cm} \mathrm{H}_{2} \mathrm{O}$ & $8(7-10)$ & $8(7-11)$ & .68 \\
\hline $\mathrm{S}_{\mathrm{pO}_{2}}, \%$ & $96(95-97)$ & $96(93-97)$ & .73 \\
\hline $\mathrm{P}_{\text {peak }}, \mathrm{cm} \mathrm{H}_{2} \mathrm{O}$ & $24(22-26)$ & $25(21-27)$ & .93 \\
\hline $\mathrm{F}_{\mathrm{IO}_{2}}, \%$ & $54(50-64)$ & $52(47-73)$ & .59 \\
\hline $\mathrm{V}_{\mathrm{T}}, \mathrm{mL} / \mathrm{kg}$ & $6.8(6.0-7.7)$ & $6.1(5.6-7.3)$ & .23 \\
\hline Breathing frequency, breaths/min & $27(23-32)$ & $30(25-38)$ & .22 \\
\hline$\overline{\mathrm{P}}_{\mathrm{aw}}, \mathrm{cm} \mathrm{H}_{2} \mathrm{O}$ & $13.7(11.9-15.7)$ & $13.4(12.0-16.6)$ & .94 \\
\hline Oxygen saturation index & $7.4(6.2-11.6)$ & $7.5(6.4-11.3)$ & .81 \\
\hline $\mathrm{V}_{\mathrm{D}} / \mathrm{V}_{\mathrm{T}}$ & $0.46(0.42-0.53)$ & $0.50(0.44-0.63)$ & .03 \\
\hline$\Delta$ PEEP, $n(\%)$ & $1(1-1)$ & $1(1-1)$ & \\
\hline$-3 \mathrm{~cm} \mathrm{H}_{2} \mathrm{O}$ & $2(4)$ & $1(2)$ & \\
\hline$-2 \mathrm{~cm} \mathrm{H}_{2} \mathrm{O}$ & $9(16)$ & $12(19)$ & \\
\hline$-1 \mathrm{~cm} \mathrm{H}_{2} \mathrm{O}$ & $45(80)$ & $51(80)$ & \\
\hline \multicolumn{4}{|c|}{$\begin{array}{l}\text { Continuous values are expressed as median (interquartile range) unless otherwise indicated. } \\
* \text { Responders were defined as those demonstrating oxygenation improvement in the first hour following the PEEP change relative to the preceding hour. } \\
\mathrm{C}_{\mathrm{dyn}}=\text { dynamic respiratory system compliance } \\
\mathrm{P}_{\text {peak }}=\text { peak airway pressure } \\
\mathrm{V}_{\mathrm{T}}=\text { tidal volume } \\
\overline{\mathrm{P}}_{\text {aw }}=\text { mean airway pressure } \\
\mathrm{V}_{\mathrm{D}}=\text { dead space volume }\end{array}$} \\
\hline
\end{tabular}

and distribution of blood flow within the lung itself. $36-38$ These factors could delay weaning and prolong duration of mechanical ventilation. The fact that we were only able to identify a single factor associated with a positive weaning response supports these reports. The use of $\mathrm{V}_{\mathrm{D}} / \mathrm{V}_{\mathrm{T}}$ has been shown to be associated with the discontinuation of pediatric mechanical ventilation. ${ }^{39}$ However, the prognostic value of using $\mathrm{V}_{\mathrm{D}} / \mathrm{V}_{\mathrm{T}}$ has not be adequately demonstrated and therefore embedding these findings into clinical practice remains difficult. 


\section{Factors Associated With PEEP Responsiveness}

There are important limitations to our study that should also be considered. The study was conducted retrospectively, and therefore the PEEP increases and decreases were not strictly controlled. Indeed, in cases where oxygenation is acceptable but chest wall compliance is poor, PEEP is increased to reduce the work of breathing. However, because this study was designed to assess the prevalence of responders and non-responders to current practice (usual care), a protocol could not be designed to ascribe specific conditions for PEEP titration. Furthermore, the prevalence of obesity-induced reductions in chest wall compliance are rare in children, especially because the cohort age, height, and weight were reasonable. The definitions for positive response to PEEP increases and decreases may not be acceptable for all patients and conditions. For instance, a stricter definition for positive response would only reduce the proportion of responders. Subjects enrolled in this study demonstrated a mix of demographics and underlying conditions; therefore, application of the findings to specific diseases may not be appropriate without further study. However, the cohort largely reflects a mix of conditions and severity of illness that is typically seen in large academic pediatric ICU environment.

\section{Conclusions}

In children requiring mechanical ventilation with hypoxic respiratory failure, the empirical probability of a positive response was not much better than the flip of a coin, ranging from $46 \%$ to $67 \%$ ). These data suggest that PEEP titration is a difficult clinical problem and that improved methods for responder identification are needed. Factors associated with a positive response include the baseline PEEP level, higher peak inspiratory pressure, higher $\mathrm{F}_{\mathrm{IO}_{2}}$, higher mean airway pressure, and increased oxygen saturation index. A reduced $\mathrm{V}_{\mathrm{D}} / \mathrm{V}_{\mathrm{T}}$ was associated with successfully decreasing PEEP. These data provide baseline performance data for PEEP titration and may provide valuable information for future methods needed to aid clinicians in identifying subjects likely to benefit from or tolerate a change in PEEP.

\section{ACKNOWLEDGMENTS}

The authors express their thanks and gratitude to John Thompson for his intellect and insight, both of which have contributed greatly to this work.

\section{REFERENCES}

1. Kallet RH. Should PEEP titration be based on chest mechanics in patients with ARDS? Respir Care 2016;61(6):876-890.

2. von Ungern-Sternberg BS, Regli A, Schibler A, Hammer J, Frei FJ, Erb TO. The impact of positive end-expiratory pressure on functional residual capacity and ventilation homogeneity impairment in anesthetized children exposed to high levels of inspired oxygen. Anesth Analg 2007;104(6):1364-1368.
3. Rimensberger PC, Pache JC, McKerlie C, Frndova H, Cox PN. Lung recruitment and lung volume maintenance: a strategy for improving oxygenation and preventing lung injury during both conventional mechanical ventilation and high-frequency oscillation. Intensive Care Med 2000;26(6):745-755.

4. Papadakos PJ, Lachmann B. The open lung concept of mechanical ventilation: the role of recruitment and stabilization. Crit Care Clin 2007;23(2):241-250.

5. Duff JP, Rosychuk RJ, Joffe AR. The safety and efficacy of sustained inflations as a lung recruitment maneuver in pediatric intensive care unit patients. Intensive Care Med 2007;33(10):1778-1786.

6. Kheir JN, Walsh BK, Smallwood CD, Rettig JS, Thompson JE, GomezLaberge $\mathrm{C}$, et al. Comparison of 2 lung recruitment strategies in children with acute lung injury. Respir Care 2013;58(8):1280-1290.

7. Cruces P, Donoso A, Valenzuela J, Diaz F. Respiratory and hemodynamic effects of a stepwise lung recruitment maneuver in pediatric ARDS: a feasibility study. Pediatr Pulmonol 2013;48(11):1135-1143.

8. Boriosi JP, Sapru A, Hanson JH, Asselin J, Gildengorin G, Newman $\mathrm{V}$, et al. Efficacy and safety of lung recruitment in pediatric patients with acute lung injury. Pediatr Crit Care Med 2011;12(4):431-436.

9. Pediatric Acute Lung Injury Consensus Conference Group. Pediatric acute respiratory distress syndrome: consensus recommendations from the Pediatric Acute Lung Injury Consensus Conference. Pediatr Crit Care Med 2015;16(5):428-439.

10. Jauncey-Cooke J, East CE, Bogossian F. Paediatric lung recruitment: a review of the clinical evidence. Paediatr Respir Rev 2015;16(2): 127-132.

11. Yehya N, Thomas NJ. Disassociating lung mechanics and oxygenation in pediatric acute respiratory distress syndrome. Crit Care Med 2017;45(7):1232-1239.

12. Amato MB, Meade MO, Slutsky AS, Brochard L, Costa EL, Schoenfeld DA, et al. Driving pressure and survival in the acute respiratory distress syndrome. N Engl J Med 2015;372(8):747-755.

13. Khemani RG, Parvathaneni K, Yehya N, Bhalla AK, Thomas NJ, Newth CJL. PEEP lower than the ARDS Network protocol is associated with higher pediatric ARDS mortality. Am J Respir Crit Care Med 2018;198(1):77-89.

14. World Health Organization. International Classification of Diseases, 9th Revision, Clinical Modification.

15. Coss-Bu JA, Walding DL, David YB, Jefferson LS. Dead space ventilation in critically ill children with lung injury. Chest 2003; 123(6):2050-2056.

16. Bhalla AK, Rubin S, Newth CJ, Ross P, Morzov R, Soto-Campos G, et al. Monitoring dead space in mechanically ventilated children: volumetric capnography versus time-based capnography. Respir Care 2015;60(11):1548-1555.

17. Clifford GD, Behar J, Li Q, Rezek I. Signal quality indices and data fusion for determining clinical acceptability of electrocardiograms. Physiol Meas 2012;33(9):1419-1433.

18. Bonafide CP, Brady PW, Keren R, Conway PH, Marsolo K, Daymont C. Development of heart and respiratory rate percentile curves for hospitalized children. Pediatrics 2013;131(4):e1150-1157.

19. Smallwood CD, Walsh BK, Arnold JH, Gouldstone A. Equilibration time required for respiratory system compliance and oxygenation response following changes in positive end-expiratory pressure in mechanically ventilated children. Crit Care Med 2018;46(5):e375-e379.

20. Hanson A, Gothberg S, Nilsson K, Hedenstierna G. Lung aeration during ventilation after recruitment guided by tidal elimination of carbon dioxide and dynamic compliance was better than after endtidal carbon dioxide targeted ventilation: a computed tomography study in surfactant-depleted piglets. Pediatr Crit Care Med 2011; 12(6):e362-e368.

21. Hanson A, Gothberg S, Nilsson K, Larsson LE, Hedenstierna G. VTCO2 and dynamic compliance-guided lung recruitment in surfac- 


\section{Factors Associated With PEEP Responsiveness}

tant-depleted piglets: a computed tomography study. Pediatr Crit Care Med 2009;10(6):687-692.

22. Wolf GK, Gomez-Laberge C, Rettig JS, Vargas SO, Smallwood CD, Prabhu SP, et al. Mechanical ventilation guided by electrical impedance tomography in experimental acute lung injury. Crit Care Med 2013;41(5):1296-1304.

23. Talmor D, Sarge T, Malhotra A, O'Donnell CR, Ritz R, Lisbon A, et al. Mechanical ventilation guided by esophageal pressure in acute lung injury. N Engl J Med 2008;359(20):2095-2104.

24. Gernoth C, Wagner G, Pelosi P, Luecke T. Respiratory and haemodynamic changes during decremental open lung positive end-expiratory pressure titration in patients with acute respiratory distress syndrome. Crit Care 2009;13(2):R59.

25. Fengmei G, Jin C, Songqiao L, Congshan Y, Yi Y. Dead space fraction changes during PEEP titration following lung recruitment in patients with ARDS. Respir Care 2012;57(10):1578-1585.

26. Caironi P, Cressoni M, Chiumello D, Ranieri M, Quintel M, Russo SG, et al. Lung opening and closing during ventilation of acute respiratory distress syndrome. Am J Respir Crit Care Med 2010; 181(6):578-586.

27. Bouhemad B, Brisson H, Le-Guen M, Arbelot C, Lu Q, Rouby JJ. Bedside ultrasound assessment of positive end-expiratory pressureinduced lung recruitment. Am J Respir Crit Care Med 2011;183(3): 341-347.

28. Pintado MC, de Pablo R, Trascasa M, Milicua JM, Rogero S, Daguerre $\mathrm{M}$, et al. Individualized PEEP setting in subjects with ARDS: a randomized controlled pilot study. Respir Care 2013;58(9):1416-1423.

29. Papastamelos C, Panitch HB, England SE, Allen JL. Developmental changes in chest wall compliance in infancy and early childhood. J Appl Physiol (1985) 1995;78(1):179-184.

30. LeVine AM, Lotze A, Stanley S, Stroud C, O'Donnell R, Whitsett J, et al. Surfactant content in children with inflammatory lung disease. Crit Care Med 1996;24(6):1062-1067.
31. Smith LS, Zimmerman JJ, Martin TR. Mechanisms of acute respiratory distress syndrome in children and adults: a review and suggestions for future research. Pediatr Crit Care Med 2013;14(6):631643.

32. Esteban A, Alia I, Ibanez J, Benito S, Tobin MJ. Modes of mechanical ventilation and weaning. A national survey of Spanish hospitals. The Spanish Lung Failure Collaborative Group. Chest 1994;106(4): 1188-1193.

33. Schultz TR, Lin RJ, Watzman HM, Durning SM, Hales R, Woodson A, et al. Weaning children from mechanical ventilation: a prospective randomized trial of protocol-directed versus physician-directed weaning. Respir Care 2001;46(8):772-782.

34. Restrepo RD, Fortenberry JD, Spainhour C, Stockwell J, Goodfellow LT. Protocol-driven ventilator management in children: comparison to nonprotocol care. J Intensive Care Med 2004;19(5):274-284.

35. Randolph AG, Wypij D, Venkataraman ST, Hanson JH, Gedeit RG, Meert KL, et al. Effect of mechanical ventilator weaning protocols on respiratory outcomes in infants and children: a randomized controlled trial. JAMA 2002;288(20):2561-2568.

36. Serafini G, Cornara G, Cavalloro F, Mori A, Dore R, Marraro G, et al. Pulmonary atelectasis during paediatric anaesthesia: CT scan evaluation and effect of positive endexpiratory pressure (PEEP). Paediatr Anaesth 1999;9(3):225-228.

37. Retamal J, Bugedo G, Larsson A, Bruhn A. High PEEP levels are associated with overdistension and tidal recruitment/derecruitment in ARDS patients. Acta Anaesthesiol Scand 2015;59(9):1161-1169.

38. Schmidt GA. Cardiopulmonary interactions in acute lung injury. Curr Opin Crit Care 2013;19(1):51-56.

39. Hubble CL, Gentile MA, Tripp DS, Craig DM, Meliones JN, Cheifetz IM. Deadspace to tidal volume ratio predicts successful extubation in infants and children. Crit Care Med 2000;28(6):2034-2040.

This article is approved for Continuing Respiratory Care Education credit. For information and to obtain your CRCE

(free to AARC members) visit www.rcjournal.com 